\title{
Knowledge, attitude, and practice of malaysian medical students towards breast cancer: A cross-sectional study
}

\author{
Siti Radziah Binti Sheikh Alaudeen ${ }^{1}$ and Kumar Ganesan ${ }^{1,2 *}$ \\ ${ }^{1}$ Faculty of Medicine, International Medical School, Management and Science University, Shah Alam-40100, Selangor, Malaysia \\ ${ }^{2}$ Department of Anaesthesiology, Li Ka Shing Faculty of Medicine, The University of Hong Kong, Hong Kong, China
}

\begin{abstract}
Objectives: Breast cancer is the second most common cancer in the world. The purpose of this study is to assess the level of knowledge, attitude and practice of breast self-examination (BSE) and breast cancer among female International Medical School (IMS) students in Management and Science University.

Methods: A cross-sectional study was conducted at IMS from April 2014 to September 2014. About 260 female students were selected randomly by a probability sampling method. A pre-tested, a self-administered validated questionnaire was used to gather data, which was analyzed using SPSS software. Chi-square test was used for analysis for categorical variables. $\mathrm{p}<0.05$ were considered significant.

Results: About $75 \%$ of the respondents $(\mathrm{N}=195)$ had overall knowledge and $89.6 \%(\mathrm{~N}=233)$ had an overall attitude towards BSE and breast cancer. About 167 respondents (64.2\%) had poor BSE practice. There was no significance between the respondents' level of knowledge and practice of BSE ( $\mathrm{p}=0.606$ ). However, the association of respondents' level of attitude and practice of BSE was found statistically significant $(\mathrm{p}=0.002)$.

Conclusion: The results indicate that the respondents had good overall knowledge and positive attitude. However, most respondents did not practice BSE. Therefore, there is certainly an immense requirement for a community health education and teaching-learning program that will inculcate the practice of BSE among young university students so that breast cancer can be reduced in Malaysia.
\end{abstract}

\section{Introduction}

Breast cancer is a malignant tumor that begins in the cells of the breast. The most common type of breast cancer is ductal carcinoma (85-90\% of all cases), which begins in the lining of the milk ducts. The other type of breast cancer is lobular carcinoma ( $8 \%$ of all cases), which begins in the lobules of the breast [1]. Breast cancer occurs in both females and males and is the most common cause of cancer death among women with 522,000 deaths in 2012 [2] It is also said to be the most frequently diagnosed cancer among women in 140 of 184 countries and represents one in four of all cancers in women. It has also reported that in 2012, 1.7 million women were diagnosed with breast cancer and there have been 6.3 million women alive who had previously been clinically determined to have breast cancer in the previous five years [2]. Furthermore, since the 2008 estimations, breast cancer frequency had increased by greater than $20 \%$, while mortality was up by $14 \%$. According to the President of the National Cancer Society of Malaysia, more than one-third of cancers are preventable and two third of cancers are curable if the cancers detected early and treated correctly. In addition, public education and screening are required for the key areas to eradicate cancers [3]. Earlier studies showed that the incidence of breast cancer in Malaysia increases gradually due to lifestyle choices, certain beliefs, lack of information, facilities, delay in early detection and treatment $[4,5]$

Breast self-examination (BSE) is a method to inspect the breast for any physical or visual changes. BSE is frequently performed for earlier detection of breast cancer. For incidence, the Mayo Clinic in Arizona researched and found in a group of 782 women, that women below 50 years of age are prone to getting a lump, which can be found during the
BSE as compared to their cancer detected in screening mammography [6]. Thus, it is undeniable that breast cancer is a women's health issue that has received serious attention from people around the world, including Malaysia. Hence the present study was aimed to investigate the level of knowledge, attitude, and practice of BSE and breast cancer among female International Medical School (IMS) students at Management and Science University (MSU).

\section{Materials and methods}

\section{Study design and sample size}

A cross-sectional study was conducted among Medical students of MSU, Shah Alam from April 2014 until September 2014. The study population was female students enrolled in IMS at MSU, Shah Alam. The age of students ranges from 19-29 years old. In the study, the probability sampling method (simple random sampling method) was used. A consent letter was given to all the participants where the purpose and protocol of the survey were explained to all participants and written consent was obtained from all the participants who agreed to participate in the survey. The information from the data was treated with the utmost respect and confidentiality.

${ }^{\star}$ Correspondence to: Kumar Ganesan, Department of Anaesthesiology, Li Ka Shing Faculty of Medicine, The University of Hong Kong, Hong Kong, China, Tel: +852 69362420; Email: drbiokumar@yahoo.com

Key words: breast cancer, BSC, knowledge and practice, IMS

Received: March 02, 2019; Accepted: March 18, 2019; Published: March 25 , 2019 
Sampling equation for proportion $n=\frac{z^{2} \sigma^{2}}{d^{2}}$

$\mathrm{n}=$ sample size; $\mathrm{z}=1.96 ; \sigma=$ Standard Deviation $(\mathrm{SD})$ of the estimate is 3.71 which is obtained from the previous study [7]. $\mathrm{d}=$ Precision of estimate which is 0.5

$$
n=\frac{(1.96)^{2}(3.71)^{2}}{(0.5)^{2}}
$$

$$
=260 \text { people }
$$

Thus, the sample size of 260 was chosen for this study

\section{Inclusion criteria}

a) Any female students aged between 18-29 years old enrolled at the IMS.

b) Students must be able to speak and read English fluently.

c) Students must also agree voluntarily to answer a questionnaire and cooperate in the study.

\section{Exclusion criteria}

a) All male students from IMS, MSU.

b) Female students studying courses other than that offered by the IMS.

c) Female students, who were under the age of 18 years old and above the age of 29 years old.

d) Female students, who were unable to speak and read English fluently and who refused to answer the questionnaire or cooperate in the study.

\section{Research tools and ethical consent}

The research tool for this study was a well-structured selfadministered questionnaire, which was derived from other published studies dealing with the same topic. The questionnaire was prepared based on the background information of the respondents and also their knowledge of different aspects of breast cancer, practice, and attitude of BSE [8-10]. All the necessary approvals for carrying out the research were obtained from the Ethical Committee of the IMS, MSU.

\section{Data analysis}

Knowledge score calculation: In this study, a knowledge score calculation was used to calculate questions in section $B$ of the questionnaires, which contain the respondents' knowledge of different aspects of breast cancer and BSE. Responses were measured using the nominal scale of "Yes", "No", "Don't know". The following scoring method was used: two points were given for a correct answer, one point for don't know and zero for incorrect answers. The level of knowledge was calculated by summing scores of all knowledge questions (24 questions) yielding a total score ranging from 0 to 48 and was divided into two categories as follows: Good level of knowledge $\geq 70 \%$ out of the maximum and poor level of knowledge $<70 \%$ out of the maximum. This scoring method was derived from the published study [9].

Attitude and practice score calculation: In the present study, the attitude score calculation was used to calculate questions in section C and $\mathrm{D}$ of the questionnaire which contained the respondents' attitude and Practice towards breast cancer and BSE. Responses were measured using a Likert type scale. For a positive attitude item, a score of " 3 ", "2" and " 1 " was used to agree, not sure and disagree respectively. The score was reversed for all the negative items. The level of attitude was calculated by summing scores of all attitude questions (12 questions) and practice questions (6 questions) yielding a total score ranging from 12 to 36 and 6 to 18 respectively, were divided into two categories as follows: Positive attitude and practice $\geq 70 \%$ out of the maximum and negative attitude and practice $<70 \%$ out of the maximum. This scoring method was derived from the published study [9].

\section{Statistical analysis}

All data obtained in this study was performed using the Statistical Package of Social Sciences (SPSS) software made for Windows Version 20.0. Descriptive statistics (frequencies and percentages) were used to describe the variables and background information of the respondents. Cross-tabulated, chi-square test, and Fisher's exact test were used to investigate associations between categorical variables. One-way chi-square goodness of fit test was used to investigate the significant categorical data. The $\mathrm{p}<0.05$ was considered as statistically significant.

\section{Results}

\section{Socio-demographic characteristics of the respondents}

The mean age of the subjects or respondents in this study was 21.4 years with a standard deviation of 3.9 years (Figure 1). The subject groups were multiracial and of different religious background which reflects the cosmopolitan nature of the Malaysian population (Table 1).

\section{Knowledge about symptoms, risk factors and screening of} breast cancer

The symptoms of breast cancer results showed that $78.5 \%(\mathrm{~N}=204)$ of respondents had overall knowledge. The majority of the respondents answered that lumps in the breast are amongst the symptoms of breast cancer (91.2\%) and swelling of the axillary lymph nodes (86.9\%) (Table 2). The results of the other symptoms of breast cancer were nipple retraction (66.9\%), puckering of the skin of the breast (65.4\%), and bloody discharge from the nipple (61.5\%). Also, it was noted that $40.8 \%$ of the respondents answered that weight gain is not a symptom associated with breast cancer (Table 2). About $45.8 \%$ of the respondents had good knowledge and $54.2 \%$ had poor knowledge concerning risk factors of breast cancer. The highest proportion (90.4\%) of the respondents in this study wrote a family history of breast cancer as the risk factors (Table 2). The respondents answered the onset of menses, before 12 years old $(31.9 \%)$ and menopause occurs in after 55 years old (61.2\%). Furthermore, $58.5 \%$ of the respondents answered that high-fat diets were one of the risk factors of breast cancer. About $40 \%$ of the respondents answered that young age $(<40$ years old) is not a risk factor for breast cancer. The methods of screening for breast cancer results revealed that about $83.1 \%$ of the respondents had an overall good level of knowledge and $16.9 \%$ of participants showed inadequate overall

Table 1. Various races of respondents in the study

\begin{tabular}{|c|c|c|}
\hline Race & No of Respondent(s) & $\mathbf{\%}$ \\
\hline Malay & 174 & 66.9 \\
\hline Chinese & 5 & 1.9 \\
\hline Indian & 68 & 26.2 \\
\hline Iban & 1 & 0.4 \\
\hline Dusun & 3 & 1.2 \\
\hline Idahan & 1 & 0.4 \\
\hline Pakistani & 3 & 1.2 \\
\hline Kadazan & 3 & 1.2 \\
\hline Bajau & 2 & 0.8 \\
\hline Total & 260 & 100.0 \\
\hline
\end{tabular}



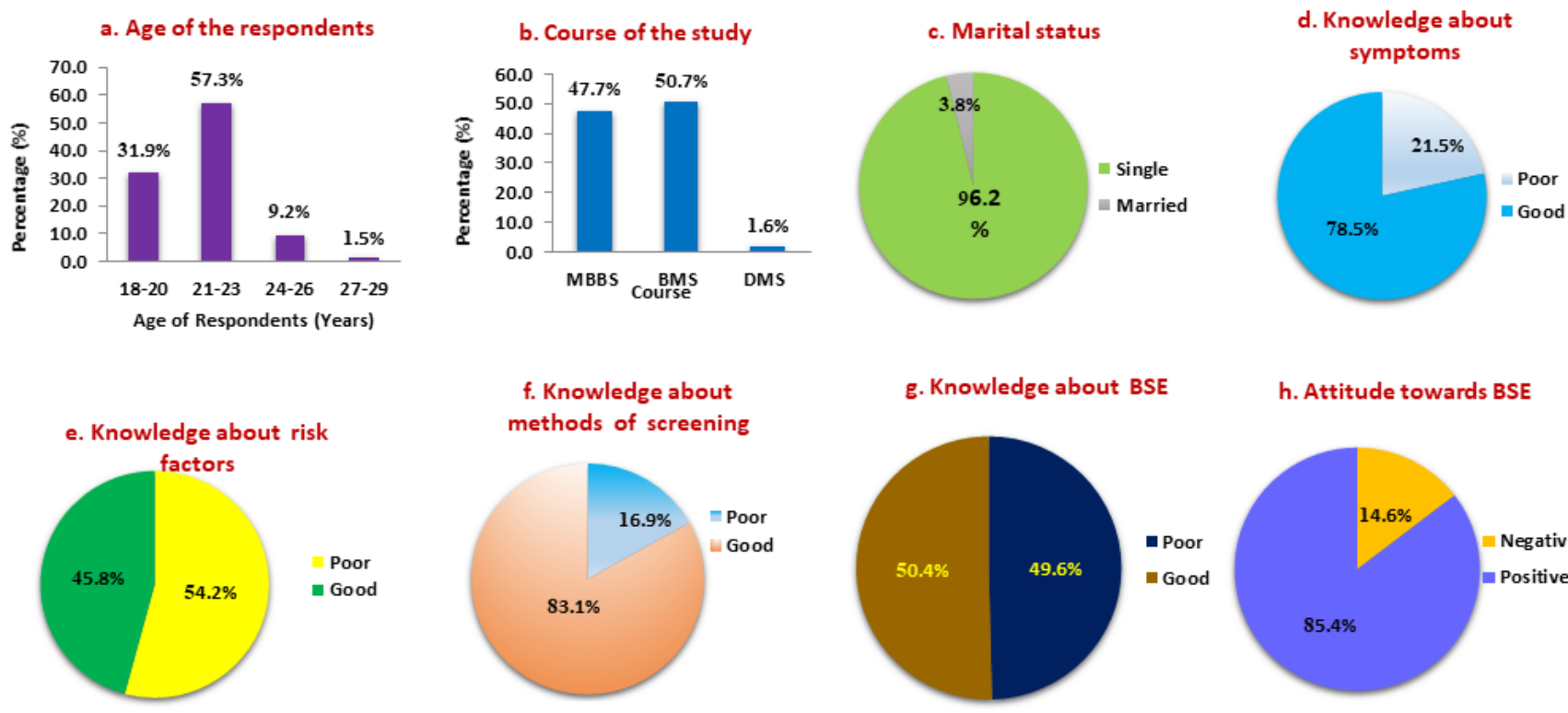

\section{h. Attitude towards BSE}

j. Practice of BSE cancer
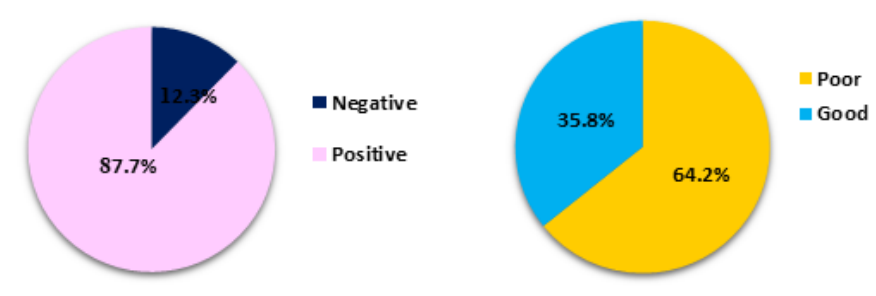

Figure 1. Knowledge, attitude, and practice of medical students towards breast cancer

Table 2. Distribution of correct, incorrect and don't know answers for knowledge of breast cancer symptoms, risk factors, method of screening, BSE among the respondents

\begin{tabular}{|c|c|c|c|c|c|c|c|}
\hline & & \multicolumn{2}{|c|}{ Correct } & \multicolumn{2}{|c|}{ Incorrect } & \multicolumn{2}{|c|}{ Don't know } \\
\hline & & No & $\%$ & No & $\%$ & No & $\%$ \\
\hline \multirow{6}{*}{ 总 } & Lump(s) in the breast & 237 & 91.2 & 12 & 4.6 & 11 & 4.2 \\
\hline & Nipple retraction (nipple pulled inward) & 174 & 66.9 & 38 & 14.6 & 48 & 18.5 \\
\hline & Bloody discharge from the nipple & 160 & 61.5 & 47 & 18.1 & 53 & 20.4 \\
\hline & Puckering (irregular fold) of the skin of the breast & 170 & 65.4 & 29 & 11.2 & 61 & 23.5 \\
\hline & Swelling of the axillary lymph nodes & 226 & 86.9 & 18 & 6.9 & 16 & 6.2 \\
\hline & Weight gain ${ }^{\#}$ & 106 & 40.8 & 51 & 19.6 & 103 & 39.6 \\
\hline \multirow{6}{*}{ 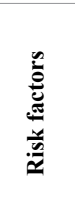 } & Young age $(<40 \text { years old })^{\#}$ & 103 & 39.6 & 117 & 45.0 & 40 & 15.4 \\
\hline & Onset of menses, before 12 years old & 83 & 31.9 & 110 & 42.3 & 67 & 25.8 \\
\hline & Menopause after 55 years old & 159 & 61.2 & 54 & 20.8 & 47 & 18.1 \\
\hline & Diets high in fat & 152 & 58.5 & 48 & 18.5 & 60 & 23.1 \\
\hline & Family history of breast cancer & 235 & 90.4 & 13 & 5.0 & 12 & 4.6 \\
\hline & Past history of breast cancer & 232 & 89.2 & 18 & 6.9 & 10 & 3.8 \\
\hline \multirow{6}{*}{ 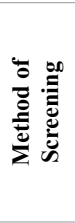 } & Breast Self-Examination & 254 & 97.7 & 3 & 1.2 & 3 & 1.2 \\
\hline & Clinical Breast Examination & 252 & 96.9 & 7 & 2.7 & 1 & 0.4 \\
\hline & Pap smears test ${ }^{\#}$ & 160 & 61.5 & 59 & 22.7 & 41 & 15.8 \\
\hline & Fine needle aspiration & 98 & 37.7 & 64 & 24.6 & 98 & 37.7 \\
\hline & Mammography & 229 & 88.1 & 7 & 2.7 & 24 & 9.2 \\
\hline & Magnetic Resonance Imaging (MRI) & 174 & 66.9 & 30 & 11.5 & 56 & 21.5 \\
\hline \multirow{6}{*}{ 窑 } & BSE is recommended to be done monthly & 181 & 69.6 & 32 & 12.3 & 47 & 18.1 \\
\hline & Suitable time to do BSE is the $7^{\text {th }}$ day after the start of menstruation & 116 & 44.6 & 24 & 9.2 & 120 & 46.2 \\
\hline & BSE is done in front of the mirror only ${ }^{\#}$ & 94 & 36.2 & 118 & 45.4 & 48 & 18.5 \\
\hline & Axilla should be examined while doing BSE & 195 & 75.0 & 11 & 4.2 & 54 & 20.8 \\
\hline & Palm of the hands should be used while doing BSE & 179 & 68.8 & 36 & 13.8 & 45 & 17.3 \\
\hline & BSE could be done in the supine position & 130 & 50.0 & 51 & 19.6 & 79 & 30.4 \\
\hline
\end{tabular}

\#Reversed knowledge question (the correct answer is No) 
knowledge. The majority of the respondents in this study answered that BSE (97.7\%) clinical breast examination (96.9\%), mammography (88.1\%), Magnetic Resonance Imaging (MRI) (66.9\%), pap smear test $(61.5 \%)$ and fine needle aspiration test (37.7\%) were the methods of screening for breast cancer (Table 2)

\section{Knowledge of BSE}

Table 2 showed that about 50.4\% $(\mathrm{N}=131)$ of this study had a good level of knowledge about BSE. The current study also revealed about knowledge of BSE that, $75.0 \%, 69.6 \%, 68.8 \%, 50.0 \%, 44.6 \%$ and $36.2 \%$ of the respondents correctly answered axilla should be examined while doing BSE, BSE is recommended to be done monthly, palm of the hands should be used while doing BSE, BSE could be done in the supine position, suitable time to do BSE is the $7^{\text {th }}$ day after the start of menstruation and BSE is done in front of the mirror only, respectively.

\section{Attitude towards BSE and breast cancer}

The results showed in this study that $85.4 \%$ of the respondents had a positive attitude towards BSE. On individual items of attitude towards BSE, the current study revealed that $73.8 \%, 89.6 \%$ and $73.8 \%$ of the respondents disagreed with the negative statements: BSE will embarrass to me, doing BSE is wasting my time and avoid BSE because I worry about having breast cancer, respectively (Table 3 ). In addition, this study also showed that $65.4 \%, 46.5 \%$ and $84.2 \%$ of the respondents agreed with the positive statements: I am interested to do BSE, I always search for information regarding BSE from the internet magazines and newspaper and all women should do BSE, respectively. About $87.7 \%$ of the respondents in this study had a positive attitude; breast cancer patients should be provided with support and home care of the community (88.8\%); punishment from God (88.1\%); breast cancer patients should be allowed to live freely in the community $(84.2 \%)$ towards breast cancer. About $47.7 \%$ of the respondents disagreed that women should be afraid of breast cancer and $32.7 \%$ of the respondents agreed that breast cancer patients should not be allowed to breastfeed (Table 3).

\section{Practice of BSE}

Table 4 showed that about $64.2 \%$ of the respondents $(\mathrm{N}=167)$ in this study had shown poorly in the practice of BSE. More than half of the respondents $(57.7 \%)$ answered never to the negative statements that I avoid learning the correct method of BSE yet only $11.2 \%$, $15.0 \%, 12.7 \%, 10.4 \%$ and $19.6 \%$ of the respondents had answered always for positive statements: I do BSE once a month, my parents or partner always advises to do BSE, I advise friends to do BSE, I discuss the importance of BSE with friends and I have been taught on BSE by health staff (Table 4).

\section{Association between the level of knowledge about BSE and practice of BSE}

In this study, the association between level of knowledge and practice of BSE was found to be not statistically significant $\left(\chi^{2}=0.307, \mathrm{p}=0.606\right)$. As only $37.4 \%(\mathrm{~N}=49)$ of the respondents had good knowledge with good practice of BSE, while most of the respondents $62.6 \%(\mathrm{~N}=82)$ had good knowledge with the poor practice of BSE (Table 5).

\section{Association between the level of attitude towards BSE and practice of BSE}

In this study, the association between level of attitude towards BSE and the practice of BSE was found to be statistically significant $\left(\chi^{2}=9\right.$. $904, \mathrm{p}=0.002)$. As the majority, $60.4 \%(\mathrm{~N}=134)$ of the respondents had a positive attitude towards BSE with the good practice of BSE (Table 5).

\section{Discussion}

\section{Socio-demographic characteristics of the respondents}

Mean age of the subject is consistent with the study of female university students in Malaysia, which is 22 years with a standard deviation of 2.3 years [11] Similarly, another study reported that the mean age of female undergraduate medical students in Taif, Saudi Arabia is 19.9 years with a standard deviation of 1.5 years [12] The study was ideal in this particular age group since most of them are young adults who really should gather more information and be aware of breast cancer as well as BSE before they reach the age of frequent occurrence of breast cancer. The present study involved respondents with a biological/health science background from IMS (Figure 1), which is consistent with the previous study among the female medical students of University of Lagos [13]. Students among participants with a medical background are appropriate as most of them are going to be the future health personnel who ought to possess adequate and accurate knowledge about breast cancer as well as BSE. Almost all of the respondents in this study were unmarried (96\%) (Figure 1) which is consistent with mean age as well as the educational level. A similar finding reported recently on young Saudi university students from health-related programmes showed approximately $93 \%$ of them were unmarried [14].

Table 3. Distribution of disagree, not sure and agree answers on attitude towards BSE and breast cancer among the respondents

\begin{tabular}{|c|c|c|c|c|c|c|c|}
\hline & & \multicolumn{2}{|c|}{ Disagree } & \multicolumn{2}{|c|}{ Not sure } & \multicolumn{2}{|c|}{ Agree } \\
\hline & & No & $\%$ & No & $\%$ & No & $\%$ \\
\hline \multirow{6}{*}{ 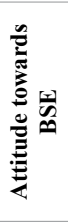 } & BSE will be embarrassing to $\mathrm{me}^{\#}$ & 192 & 73.8 & 44 & 16.9 & 24 & 9.2 \\
\hline & Doing BSE is wasting my time $\mathrm{f}^{\#}$ & 233 & 89.6 & 22 & 8.5 & 5 & 1.9 \\
\hline & Avoid BSE because I worry about having breast cancer ${ }^{\#}$ & 192 & 73.8 & 42 & 16.2 & 26 & 10.0 \\
\hline & I am interested to do BSE & 30 & 11.5 & 60 & 23.1 & 170 & 65.4 \\
\hline & I always search for information regarding BSE from the internet, magazines and newspaper & 53 & 20.4 & 86 & 33.1 & 121 & 46.5 \\
\hline & All women should do BSE & 21 & 8.1 & 20 & 7.7 & 219 & 84.2 \\
\hline \multirow{6}{*}{ 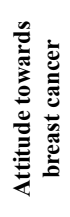 } & Breast cancer patients should be isolated ${ }^{\#}$ & 216 & 83.1 & 25 & 9.6 & 19 & 7.3 \\
\hline & Breast cancer is a punishment from God ${ }^{\#}$ & 229 & 88.1 & 16 & 6.2 & 15 & 5.8 \\
\hline & Women should be afraid of breast cancer ${ }^{\#}$ & 124 & 47.7 & 36 & 13.8 & 100 & 38.5 \\
\hline & Breast cancer patients should be allowed to live freely in the community & 28 & 10.8 & 13 & 5.0 & 219 & 84.2 \\
\hline & Breast cancer patients should be provided with support and home care by the community & 13 & 5.0 & 16 & 6.2 & 231 & 88.8 \\
\hline & Breast cancer patients should not be allowed to breastfeed & 25 & 9.6 & 150 & 57.7 & 85 & 32.7 \\
\hline
\end{tabular}

\#Negative item (the scoring will be reversed) 
Table 4. Distribution of always, sometimes and never answers to practice of BSE among the respondents

\begin{tabular}{|c|c|c|c|c|c|c|c|}
\hline \multirow[t]{2}{*}{ S.No } & \multirow[t]{2}{*}{ Practice of BSE } & \multicolumn{2}{|c|}{ Always } & \multicolumn{2}{|c|}{ Sometimes } & \multicolumn{2}{|c|}{ Never } \\
\hline & & No & $\%$ & No & $\%$ & No & $\%$ \\
\hline 1 & I avoid learning the correct method of BSE & 17 & 6.5 & 93 & 35.8 & 150 & 57.7 \\
\hline 2 & I do BSE once a month & 29 & 11.2 & 137 & 52.7 & 94 & 36.2 \\
\hline 3 & My parents or partner always advise to do BSE & 39 & 15.0 & 130 & 50.0 & 91 & 35.0 \\
\hline 4 & I advise friends to do BSE & 33 & 12.7 & 125 & 48.1 & 102 & 39.2 \\
\hline 5 & I discuss the importance of BSE with friends & 27 & 10.4 & 147 & 56.5 & 86 & 33.1 \\
\hline 6 & I have been taught on BSE by health staff & 51 & 19.6 & 131 & 50.4 & 78 & 30.0 \\
\hline
\end{tabular}

Table 5. Chi-square analysis of association between levels of knowledge and attitude about BSE with the level of practice of BSE among the respondents

\begin{tabular}{|c|c|c|c|c|c|c|c|}
\hline \multirow{2}{*}{ Variable } & \multirow{2}{*}{\multicolumn{2}{|c|}{ Level of practice of BSE }} & \multirow{3}{*}{$\chi^{2}$} & \multirow{3}{*}{$\mathbf{p}^{*}$} & \multirow{3}{*}{ Odd ratio } & \multicolumn{2}{|c|}{ 95\% Confidence Interval } \\
\hline & & & & & & $\mathrm{L}$ & $\mathrm{U}$ \\
\hline \multirow{3}{*}{ Level of knowledge about BSE } & $\begin{array}{c}\text { Poor } \\
\text { no (\%) }\end{array}$ & $\begin{array}{c}\text { Good } \\
\text { no (\%) }\end{array}$ & & & & & \\
\hline & $85(65.9 \%)$ & $\begin{array}{c}44 \\
(34.1 \%)\end{array}$ & \multirow[t]{2}{*}{0.307} & \multirow[t]{2}{*}{0.606} & \multirow[t]{2}{*}{1.154} & \multirow[t]{2}{*}{0.695} & \multirow[t]{2}{*}{1.918} \\
\hline & $82(62.6 \%)$ & $49(37.4 \%)$ & & & & & \\
\hline \multirow{3}{*}{ Level of attitude about BSE } & $\begin{array}{c}\text { Poor } \\
\text { no (\%) }\end{array}$ & $\begin{array}{c}\text { Good } \\
\text { no (\%) }\end{array}$ & & & & & \\
\hline & $05(13.2 \%)$ & $33(86.8 \%)$ & 9.904 & 0.002 & 4.334 & 1.630 & 11.529 \\
\hline & $88(39.6 \%)$ & $134(60.4 \%)$ & & & & & \\
\hline
\end{tabular}

$\mathrm{p}^{*}:$ Fisher's Exact Test

\section{Knowledge about symptoms of breast cancer}

About 78.5 percentages of the respondents had overall good knowledge about breast cancer (Figure 1). On the contrary, a lower overall knowledge score of $50.9 \%(\mathrm{~N}=169)$ was reported in the study that was carried out among the female staff of a public university in Malaysia [8]. However, a recent study reported a much smaller that is only $14.6 \%(\mathrm{~N}=55)$ of the respondents had a good level of knowledge [12]. The results of symptoms had better than the findings of previous study symptoms of nipple retraction (29\%), puckering of the skin of the breast (32.5\%) and bloody discharge from the nipple $(50.2 \%)$ [12] Majority of the respondents (91.2\%) answered correctly about the symptoms of breast cancer and this is greater than the findings of various other studies accomplished in Kuwait (88.8\%) [15], Oman (88.5\%) [16], Malaysia (84.6\%) [7,9] and Egypt (81.6\%) [17]

About $41 \%$ of the respondents in the present study answered as weight gain is not a symptom associated with breast cancer and that was almost similar to the result of an earlier study done in Malaysia (46.4\%) [8]. The highest percentage of respondents who could identify correctly the symptoms of breast cancer and the high overall knowledge $(78.5 \%)$ is encouraging since a study in the year 2011 had shown that lack of knowledge about symptoms of breast cancer can contribute to delay in detection, treatment, and prognosis of breast cancer in Malaysia [18].

\section{Knowledge about risk factors of breast cancer}

About $45.8 \%$ of the respondents in the study exhibited less knowledge about the risk factors of breast cancer (Figure 1). A survey of women in Cameroon, Africa showed a similar pattern as observed in this study that is $45 \%$ of respondents were substantially aware, while $50 \%$ were partially aware and 5\% were totally not aware of the risk factors of breast cancer [19] More than $90 \%$ of the respondents in this study were aware of a family history of breast cancer as the highest risk factors. This result is consistent with the study done in Malaysia with $91.5 \%$ [7]. The second highest score of $89.2 \%$ was observed in the past history of breast cancer as amongst the risk factors of breast cancer. However, a slightly lower value of $71.4 \%$ was stated another study done in Malaysia [8] Findings from the study suggested that more Malaysian women are becoming aware of the influence of genes or inheritance as risk factors of breast cancer.

The onset of menses is one of the risk factors of breast cancer; this is much higher in our present result $(32.9 \%)$ than the finding as reported before (7.4\%) [17]. Furthermore, menopause usually occurs in after 55 years old and this finding is greater $(61.2 \%)$ than the results of various other studies done in Ghana (24.2\%) [20] and in Malaysia 30\% [8] These suggest that young respondents are more aware of the role of hormones as an important influential factor of breast cancer. The results of a diet high in fat obtained in this study are lower than the reported earlier (63.3\%) [8] but much higher (36.3\%) than from Egypt [21]. In fact, the influence of nutrients, including fatty acids on mammary gland development and breast cancer is actively investigated in a new domain of nutrition called nutrigenomics [22] In addition, young age is not a risk factor for breast cancer which is lower than the results of a study conducted previously in Malaysia (54.2\%) [8] Thus, early education regarding breast health will benefit the younger generation of women including university students.

\section{Knowledge about methods of screening for breast cancer}

In our study, more than $83 \%$ of the participants had good knowledge about methods of screening for breast cancer (Figure 1). However, these studies carried out in Qom, Iran showed only $61.9 \%$ of respondents had a good level of knowledge [23] About $97 \%$ the respondents showed that the method of screening of breast cancer by BSE in this study and this specific finding is higher than previous findings like 12.6\% [24], 19\% [25], 74.2\% [17], 81.4\% [26] respectively.

\section{Knowledge of BSE}

Approximately half of the total respondents had a good knowledge of BSE in this study (Figure 1). In contrast, a study executed among female medical students in Taif, Saudi Arabia obtained a much lower percentage (8.2\%) [12]. When the knowledge about BSE results compared with a prior study [12], which stated that the proportion of respondents answered more than $60 \%$, and these findings are greater than the current study. 


\section{Attitude towards BSE}

The results showed that more than $85 \%$ of the respondents had a positive attitude towards BSE and breast cancer (Figure 1) compared with previous studies (67\%) done among female medical students in Taif, Saudi Arabia [12] and women from Terengganu (73.3\%) in Malaysia [9]. In the present study, the attitude towards breast cancer finding was less than the previous study done with $<90 \%$ [27], $91.9 \%$, $67.0 \%$, and $72.3 \%$ [10] respectively. It reflects the feeling of empathy among the respondents in the present and previous studies. The findings of women should be afraid of breast cancer this is still higher (47.7\%) than the findings of a previous study, where only $10.5 \%$ [10]. But the result of 'breast cancer patients should not be allowed to breastfeed' is lower $(32.7 \%)$ than the result of the previous study (56.4\%) conducted in Northeast Nigeria [10]

\section{Practice of BSE}

Majority of the respondents [64. 2\% $(\mathrm{N}=167)]$ in the present study exhibited poor in the practice of BSE (Figure 1), this is much better than the finding of a previous study among women $[93.0 \%(\mathrm{~N}=80)]$ in a suburban area in Terengganu, Malaysia [9]. The results, which obtained in the present study were not comparable to other published reports since their results are represented as mean marks of respondents.

\section{Association between the level of knowledge about BSE and} practice of BSE

In the present study, the association between level of knowledge and practice of BSE findings were consistent with the study conducted among Nigerian female cleaners at Obafemi Awolowo University, Nigeria, which reported that there was found not to be statistically significant $\left(\chi^{2}=9.31, \mathrm{p}=0.16\right)$ [28].

\section{Association between the level of attitude towards BSE and practice of BSE}

In this study, the association between level of attitude and practice of BSE findings were consistent with the study conducted in Nigeria among secondary school teachers [29], which reported that it was statistically significant $(\mathrm{p}=0.019)$.

\section{Conclusion}

There is certainly an immense requirement for a community health education and teaching-learning program that will inculcate the practice of BSE among the young university students. Every effort needs to be more practical in order to encourage the practice of BSE. It is evident from the present study that less than $20 \%$ of respondents were taught by health staff on BSE. Thus, health care professionals who include grass root level health workers should play a significant role in educating the public in general and the high-risk women in particular, especially the $13 \%$ females with a family history of breast cancer as found in this study. This will also broaden the knowledge and create early awareness of BSE and breast cancer. The involvement of community, family, especially parents as well as spouse need to be facilitated to maximize the understanding of BSE. This study suggests only about $15 \%$ of participants are advised to do BSE by parents or partner. Nongovernmental organizations could be roped in rural areas for this initiative. In addition to that, family physicians should be encouraged to boost awareness; provide clear and specific guidance on the practice of BSE as well as promote referral as well. These may decrease the mortality and morbidity due to breast cancer among female patients and can contribute towards better female life expectancy in Malaysia.

\section{Limitations of the current study}

There are several limitation elements have been recognized within this study. One of the limitations is the sample population. Although the sample size was more than sufficient in numbers for the present study, the sample was derived from only one faculty which is from the IMS owing to the short duration of the study. The female students of IMS are from health /biological science background which may differ from other faculties with management or arts background and therefore it cannot be generalized to represent the female students of MSU. Thus, samples of female students from various other faculties must be included so that the sample population may represent the Malaysian university student populations. Another limitation of the study is that the targeted population was only female students. It somehow restricted the male students' opportunity of knowing or learning about these issues of BSE and breast cancer. It is only fair that male students be included in this type of study so that they may in future provide assistance and make aware if they encounter somebody suffering from breast cancer either in their family or community. Most importantly, the duration of the study must be extended slightly more in order to strengthen the findings and include the limitations as stated above.

\section{Acknowledgements}

The authors are thankful to Dean, Deputy Dean and Faculty members of International Medical School, Management and Science University, Shah Alam, Malaysia for providing facilities and support for the research work.

\section{Conflicts of interest}

The authors declare that there are no conflicts of interest.

\section{References}

1. Landercasper J, Ramirez LD, Borgert AJ, Ahmad HF, Parsons BM, et al. (2019) A reappraisal of the comparative effectiveness of lumpectomy versus mastectomy on breast cancer survival: a propensity score-matched update from the national cancer data base (NCDB). Clin Breast Cancer 18: 861-869.

2. Cedolini C, Bertozzi S, Londero AP, Bernardi S, Seriau L, et al. (2014) Type of breas cancer diagnosis, screening, and survival. Clin Breast Cancer 14: 235-240. [Crossref]

3. Yazdani-Charati R, Hajian-Tilaki K, Sharbatdaran M (2019) Comparison of pathologic characteristics of breast cancer in younger and older women. Caspian J Intern Med 10: 42-47. [Crossref]

4. Yip CH, Taib NA, Mohamed I (2006) Epidemiology of breast cancer in Malaysia Asian Pac J Cancer Prev 7: 369-374. [Crossref]

5. Sukalingam K, Ganesan K (2016) Health-related quality of life in young adult girls with dysmenorrhea among university medical students in Shah Alam, Malaysia: A cross-sectional study. Recent Adv Biol Med 2: 121-127.

6. Almerey T, Villacreses D, Li Z, Patel B, McDonough MA, et al. (2019) Value of axillary ultrasound after negative axillary mri for evaluating nodal status in high-risk breast cancer. J Am Coll Surg 19: 154-160. [Crossref]

7. Hadi M, Hassali M, Shafie A, Awaisu A (2010) Evaluation of breast cancer awareness among female university students in Malaysia. Pharma Pract 8: 29-34.

8. Nor Afiah MZ, Hejar AR, Looi YK, Lim SJ, Ng CY, et al. (2011) Breast cancer screening: How knowledgeable are female staff of a public university? Int Med $J$ Malaysia 10: 23-30.

9. Nik Rosmawati NH (2010) Knowledge, attitude and practice of breast self-examination among women in a suburban area in terengganu, malaysia. Asian Pac J Cancer Prev 11: $1503-1508$

10. Omotara B, Yahya S, Amodu M, Bimba J (2012) Awareness, attitude, and practice of rural women regarding breast cancer in northeast nigeria. J Comm Med Health Educ 2: 148 .

11. Akhtari-Zavare M, Juni MH, Manaf RA, Ismail IZ, Said S (2011) Knowledge on breast cancer and practice of breast self-examination among selected female university students in Malaysia. Med Hlth Sci J 7: 49-56. 
12. Nemenqani DM, Abdelmaqsoud SH, Al-Malki AA, Oraija AA, Al-Otaibi EM (2014) Knowledge, attitude and practice of breast self-examination and breast cancer among female medical students in Taif, Saudi Arabia. Open J Prev Med 4: 69-77.

13. Irurhe N, Olowoyeye O, Arogundade R, Bassey R, Onajole A (2009) Knowledge, attitude and practice of breast self-examination among female medical students in the university of lagos. Internet $J$ Hlth 12: 1-10.

14. Latif R (2014) Knowledge and attitude of saudi female students towards breast cancer: A cross-sectional study. J Taibah Univ Med Sci 9: 328-334

15. Alharbi N, Alshammari M, Almutairi B, Makboul G, El-Shazly M (2012) Knowledge, awareness, and practices concerning breast cancer among Kuwaiti female school teachers. Alexandria J Med 48: 75-82.

16. Al Junaibi RM, Khan SA (2011) Knowledge and awareness of breast cancer among university female students in Muscat, Sultanate of Oman-A pilot study. J Appl Pharma Sci 1: 146-149.

17. Boulos DNK, Ghali RR (2013) Awareness of breast cancer among female students at ain shams university. Egypt Glob J Hlth Sci 6: 154-161.

18. Norsa'adah B, Rampal KG, Rahmah MA, Naing NN, Biswal BM (2011) Diagnosis delay of breast cancer and its associated factors in Malaysian women. BMC Cancer 11: 141. [Crossref]

19. Suh MA, Atashili J, Fuh EA, Eta VA (2012) Breast self-examination and breast cancer awareness in women in developing countries: a survey of women in Buea, Cameroon. BMC Res Notes 5: 627. [Crossref]

20. Ohene-Yeboah M, Adofo K, Akpaloo M (2013) Breast cancer awareness among nurses in Kumasi Ghana: knowledge, attitudes, and practice. Postgrad Med J Ghana $2: 3-10$
21. Abdel-Fattah M, Zaki A, Bassili A, El-Shazly M, Tognoni G (2000) Breast selfexamination practice and its impact on breast cancer diagnosis in Alexandria. Egypt East Mediterr Hlth J 6: 34-40.

22. MacLennan M, Ma DW (2010) Role of dietary fatty acids in mammary gland development and breast cancer. Breast Cancer Res 12: 211. [Crossref]

23. Karimian Z, Mehran N, Haddad Z (2009) The assessment of knowledge, attitude, and behavior of women in qom toward breast cancer screening methods. Res $J$ Med Sci 4:116-118.

24. Turjaka A, Berisha M, Luci L, Lulaj S (2010) Breast cancer screening in Kosovo: women's knowledge and behaviors. Slovenian J Publ Hlth 49: 153-159.

25. Habib F, Salman S, Safwat M, Shalaby S (2010) Awareness and knowledge of breas cancer among university students in Al Madina Al Munawara Region. Middle East $J$ Cancer 1: 159-166.

26. Dellie ST, Neguse TM, Demissie M, Rao AD (2012) Knowledge about breast cancer risk-factors, breast screening method and practice of breast screening among female healthcare professionals working in governmental hospitals, addis ababa, ethiopia. IOSR J Pharma Biol Sci 2: 5-12.

27. Gilani SI, Khurram M, Mazhar T, Mir ST, Ali S, et al. (2010) Knowledge, attitude and practice of a Pakistani female cohort towards breast cancer. JPMA. J Pak Med Assoc 60: 205-208.

28. Alice TE, Philomena OK (2014) Breast self-examination among secondary schoo teachers in South-South, Nigeria: A survey of perception and practice. J Publ Hlth Epidemiol 6: 169-173.

29. Omoyeni OM, Oluwafeyikemi PE, Irinoye OO (2014) Assessment of the Knowledge and Practice of Breast Self-Examination among Female Cleaners in Obafemi Awolowo University Ile Ife, Nigeria. Int J Caring Sci 7: 239-251.

Copyright: (C2019 Alaudeen SRBS. This is an open-access article distributed under the terms of the Creative Commons Attribution License, which permits unrestricted use, distribution, and reproduction in any medium, provided the original author and source are credited. 